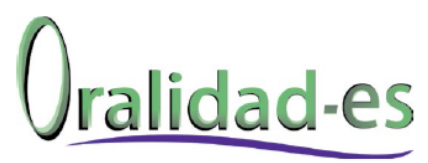

\title{
"Hagámonos contar". Estrategia pedagógica para el fortalecimiento de las competencias comunicativas y el reconocimiento de valores locales en estudiantes de secundaria
} Let's make ourselves count. Pedagogical strategy for the strengthening of communication skills and the recognition of local values in high school students

Sindy Judith Panza de la Hoz sindypanzadh@hotmail.com Institución Educativa Nuestra Señora de la Candelaria, Colombia

Panza de la Hoz, S. J. (2018). “Hagámonos contar”. Estrategia pedagógica para el fortalecimiento de las competencias comunicativas y el reconocimiento de valores locales en estudiantes de secundaria. Oralidad-es, 4, 1-8. https://revistaoralidad-es.com/index.php/ro-es/article/view/108/79 


\section{Resumen}

Hagámonos contar es una guía docente para abordar la lectura del texto Vean vé mis nanas negras de la escritora y narradora oral chocoana, Amalia Lú Posso Figueroa. La propuesta pedagógica tiene como eje unas actividades que permitan fortalecer las habilidades de estudiantes de secundaria (11 a 18 años) frente a las distintas manifestaciones orales de su entorno así como para ampliar su perspectiva acerca de la importancia de las mismas.

\section{Palabras Clave}

Oralidad; pedagogía; entorno; realidad; afrodescen-

\section{Abstract}

Let us tell is a teaching guide to address the reading of the text Vean vé mis nanas negras from the writer and oral narrator Chocoana, Amalia Lú Posso Figueroa. The pedagogical proposal has as its axis activities that strengthen the skills of secondary school students (11 to 18 years old) in the face of the different oral manifestations of their environment as well as to broaden their perspective on the importance of them.

Keywords

Orality; pedagogy; environment; reality; afrodescendencia 
"Hagámonos contar" es una estrategia pedagógica para el fortalecimiento de las competencias comunicativas en estudiantes de secundaria (11 a 18 años) con dificultades académicas y convivenciales a partir de la relación entre la lectura, escritura y oralidad presente en el texto Vean vé mis nanas negras de Amalia Lu Posso Figueroa. Se propone que la muestra poblacional para aplicar la estrategia sean aquellos estudiantes que no sobresalen en las actividades académicas regulares del aula de clases ni en las actividades institucionales como actos culturales, cívicos, festivales, competencias o actividades en equipo y que por estas mismas circunstancias a menudo son reconocidos o focalizados como estudiantes problema, con dificultades académicas y convivenciales.

De esta manera, la estrategia va enfocada a la mejora de comportamientos inadecuados que lejos de tener su origen en conductas de rebeldía de los educandos, radican en estas mismas dificultades académicas y en el sentimiento de falta de capacidad o aceptación generado, en muchos casos, por procesos académicos que no tienen en cuenta sus características específicas de aprendizaje. En otras palabras es una propuesta inspirada en los estudiantes que en sus actitudes de rebeldía, pereza, desinterés o dificultad de aprendizaje reflejan baja autoestima y timidez para participar, preguntar o pedir ayuda; estudiantes que pasan un año tras otro con promedio bajo o básico sin hacerse notar en el salón de clases ni en la institución y que debido a su quietud y comportamiento callado no reprueban, pero tampoco desarrollan todo su potencial académico y social.

Ellos, los "ni fu, ni fa" y los que distinguimos por conductas negativas son el motivo y centro de esta estrategia que lleva por nombre "Hagámonos contar", aludiendo, precisamente, a la doble connotación del término: narrar y hacerse notar, valer, tener en cuenta.
Así, para lograr la potencialización de habilidades orales como un medio para el desarrollo personal y social de la población escogida, a partir del texto de Posso Figueroa, se propone plantearse los siguientes objetivos:

- Promover la lectura y la escritura desde la propia capacidad y forma de expresión que inicia con la oralidad.

- Propiciar la superación de dificultades del proceso lecto-escritor que pueda presentar la población escogida.

- Lograr la participación de los estudiantes en actividades de aula e institucionales de manera que descubran sus fortalezas al hablar y escuchar, siendo estas, competencias fundamentales para su desarrollo social y una adecuada convivencia institucional.

- Promover actividades que involucren su comunidad de manera que puedan contribuir a la preservación de sus manifestaciones orales y en general al desarrollo sociocultural de la misma.

Para la consecución de los anteriores objetivos optaremos por el diseño y ejecución de unas guías para hacer una lectura diferente, creativa y contextual de tres historias del libro. Se hará uso de herramientas como: el trabajo colaborativo, la entrevista, la producción de textos orales y escritos, la interacción con la comunidad, el foro e implementación de tecnologías de información y comunicación.

Una vez hecha una breve descripción del libro y su autora, presentaremos cada guía de lectura que consta de título, fragmento y una descripción de la propuesta de lectura inspirada en los ritmos de las nanas; en esta última se incluyen posibles preguntas para realizar a los estudiantes. Las guías, entonces, están estructuradas de la siguiente manera: 1. Al ritmo del pensar (nana Valentina): propuestas para reflexionar sobre el texto y disponerse a llevarlo a la prácti- 
ca 2. Al ritmo de la lengua (nana Basilisa): aquí se propondrá la actividad de expresión oral y producción textual a partir de la comprensión del fragmento 3. Al ritmo de la mirada (nana Acento): se presentará la manera de evaluar y reflexionar sobre el trabajo realizado 4 . Al ritmo del talón (nana Amantina): será el espacio para pensar sobre lo que hace falta analizar y/o hacer otras propuestas de lectura crítica y creativa sobre el texto (generalmente propone preguntas para los estudiantes).

\section{El libro y su autora}

Vean vé mis nanas negras es un conjunto de 26 textos breves, con tinte humorístico y una marcada descripción, que bien pueden denominarse viñetas; presenta una construcción particular del personaje femenino negro ubicado en el Chocó como espacio diegético. En la voz del alter ego de Amalia Lu como narradora, y además personaje, se configuran mujeres que son honorables como Honoria, diosas, fieles o inmensas como en Dioselina, Fidelia y Maximina. Son mujeres sexuales y sensuales con su ritmo en las tetas, las piernas y, además, son mujeres con voz, lengua, corazón, sentimiento, pensamiento y mirada. Es decir ,con un don especial que les permite sobresalir en su entorno, ser admiradas, sentirse plenas consigo mismas y en la mayoría de los casos beneficiar a su comunidad. Vean vé mis nanas negras muestra un Chocó dibujado desde las líneas de un cuerpo de mujer, de cuerpos de nanas negras que detrás de la voz de su autora, se abren paso para contarse a sí mismas.

Uno de los grandes temas que comprende este libro es la oralidad, manifiesta en el contenido de las historias, las prácticas de los personajes y la estructura del libro (lenguaje, recursos estilísticos y recopilación de algunas expresiones orales del Pacífico). De hecho, Posso Figueroa, psicóloga de profesión, que nació y vivió en Quibdó hasta sus once años y quien escribe en el 2001 este, su único libro, que llega ya a su octava edición, ha llevado estas historias al escenario con el espectáculo de narración oral Cuentos eróticos del Pacífico colombiano, que ya ha sido presentado en escenarios de Colombia, España, Francia, Venezuela, Argentina, México, Brasil, Ecuador y Estados Unidos.

Aunque su libro ha alcanzado mayor reconocimiento por la escenificación oral que mencionábamos, el texto escrito ha sido menor objeto de análisis dentro de la crítica literaria. Krakusin (2007), Patiño (2005) y Vejarano (2012) son autoras que han puesto la mirada sobre su texto, enfocándose en temáticas como el ritmo, la oralidad, la sensualidad y el erotismo. Todos aportes muy valiosos que fueron punto de partida para mi trabajo de tesis, sobre el libro en mención, titulado: Resignificación de cuerpo y espacio en Vean vé mis nanas negras de Amalia Lú Posso Figueroa (Panza, 2018) el cual es una invitación a que dentro de nuestro ejercicio docente la lectura sea un punto de partida para la resignificación de nuestro entorno que trascienda su utilidad para el aprendizaje y nos permita también el desaprender, permitiendo a nuestros estudiantes abrirse a nuevas formas de leer tanto los textos literarios como sus realidades personales y sociales.

Dentro de algunos resultados de mi proceso investigativo estuvo la confrontación con la esencialización de "lo negro", la cual radica en creer que hay unas formas prefijadas del ser negro derivadas de lo que comúnmente se identifican como rasgos de africanidad: dentro de los cuales caben las temáticas recurrentes en los textos críticos sobre Vean vé mis nanas negras, siendo la oralidad una de ellas. Dentro de mi investigación, abordo la oralidad como posible mecanismo de apropiación o consolidación del cuerpo propio; es decir, como medio que tienen los individuos o grupos que hace uso de las manifestaciones orales para autodeterminarse, para desestructurarse de todas aquellas formas prefijadas de ser que los limitan y encasillan, para 
poder construirse a sí mismos a través del uso y creación desde todas las expresiones posibles de la oralidad entendida desde las perspectivas de Motta (1997) y Oslender (2003) quienes coinciden en proponerla como eje fundamental para la concientización de las comunidades, es decir como el espacio desde el cual se pueden defender los derechos, el territorio y el cuerpo ante las estructuras sociales. Lo que en palabras de Motta (1997) versa así:

La oralidad como fuente expresiva y forma de comunicación directa, se refiere a un conjunto de manifestaciones culturales, a los actos cotidianos de cada momento de la vida $y$ de la muerte, a los traumas, desarraigos $y$ angustias étnicas, a propuestas y respuestas sobre los acontecimientos y su próximo devenir. (p.42)

En este sentido y aludiendo a la necesidad de procesos pedagógicos críticos y humanistas se propone a continuación una guía de lectura que invite al docente a tomar los aspectos culturales dispuestos en la comunidad, en este caso la oralidad, para que los estudiantes realmente cuenten, en el doble sentido que embarga esta palabra: que sean constructores de su conocimiento, su entorno y su ser a partir de la posibilidad de narrar su realidad.

\section{Guías de lectura: Honoria}

\section{Lozano}

Hasta las bancas de la iglesia alegraban su sentar.

Pero un día cambiaron al cura de Quibdó. Llegó un manizalita blanco, de cejas negras pobladas, con ojos de mirar profundo tras unas cristalinas gafas; era joven, delgado y apuesto; su apariencia parecía en contravía con su vocación sacerdotal.
Era muy estricto y en el primer sermón dijo que rezar de rodillas o de pie y ofrecer el sacrificio de no estar sentado era la más alta entrega al altísimo, que traería recompensa si no en esta vida, en la otra.

Honoria no entendió, no podía imaginarse gozando sentada sobre una nube en la otra vida así que resolvió ir al confesionario para hablarle al cura blanco de cejas negras sobre sus dudas, para que él la tranquilizara de una vez por todas. (Fragmento tomado de Posso, 2011, p.108).

\section{Al ritmo del pensar}

Lee el fragmento y deduce la mayor cantidad de características, datos e información de la nana y el cura, haz una lista

\section{Al ritmo de la lengua}

Organizados en grupos de cuatro a seis estudiantes deben escoger dos integrantes y caracterizarlos como el cura y la nana, haciendo uso de vestuario, objetos y otros accesorios. Una vez hecho esto deben organizar un show de televisión donde la nana y el cura serán los invitados principales. Deben escribir una guía de preguntas y posibles diálogos y situaciones que no sólo recreen el fragmento, sino que vayan más allá, mostrando, tanto la interpretación e inferencias que se pueden hacer del mismo, como todas las ideas previas que se tienen sobre estos dos personajes y su contexto.

Nota: Además de tener una guía escrita, se debe incentivar y permitir la improvisación para observar y analizar la existencia de posibles estereotipos, prejuicios e ideas sobre la situación. Se recomienda, además, grabar el ejercicio para el posterior análisis de lo que surja en la improvisación.

\section{Al ritmo de la mirada}

Una vez realizado el ejercicio de improvisación teatral se propone hacer una mesa redonda alrededor de los siguientes interrogantes: ¿Cómo se 
sintió cada personaje? ¿Qué los motivó a caracterizar los personajes de esa manera y plantear esas situaciones? ¿Qué conclusiones podemos hacer acerca de las ideas que tenemos sobre las personas de piel blanca y piel negra?

Aporte reflexivo: Así como cada grupo planteó diferentes situaciones y caracterizaciones, las personas no tenemos formas ya determinadas de ser, ni debemos ser encasilladas y rotuladas tras una identidad fija por nuestro color de piel, creencias o lugar de origen.

Al ritmo del corazón

¿Qué sentí y aprendí con esta actividad?

Al ritmo del talón

¿Qué falta por hacer? ¿Qué cambiarías a la actividad propuesta? ¿Qué otra actividad podrías proponer a partir de esta lectura?

\section{Guías de lectura: Delfa y Jesusita}

Delfa García tenía el ritmo en la voz, pero en la voz contada. Eran embrujadores sus relatos eternos, pues ella los alargaba siempre para dar la dimensión exacta del tiempo y en el tiempo. Me contaba que ella había oído que un señor don Miguel A. Caicedo hacía unos cuentos muy bonitos, pero ella los refería como ella los recordaba, que era como a ella le daba su gana y asunto allá [...]

Jesusita nunca salía de su cocina cuando sentía que estaba lista la voz contada de Delfa para contar y cuando atisbaba para saber si el cuento ya se iba a acabar, se ponía la mano en su narga para iniciar un conteo de a la una, a las dos y van a ser las tres, que era un anuncio de canteo, en el cual Delfa no tenía lugar.

Ya las viejas no golpean, su tiempo pasó que golpeen las muchachas así como yo

Allá arriba en aquel alto, Simón se murió

con los güevos en la barriga, así como vos

sapo rondón, sapo rondón

sapo rondón cogé tu biberón (Fragmento tomado de Posso, 2011, 154)

\section{Al ritmo del pensar}

¿Cuál es la importancia y función que tienen los cantos y cuentos en tu localidad, en tu familia, para ti?

\section{Al ritmo de la lengua}

Organizados en grupos de cuatro realicen unos videos donde recopilen cómo en su entorno son usados los cantos y cuentos para las actividades cotidianas. Para guiar y motivar la participación en la actividad se recomiendan hacer a los entrevistados o participantes del video las siguientes preguntas: ¿Qué es para ti la oralidad? ¿Qué importancia tiene cantar o contar historias en tus actividades cotidianas? ¿Durante qué actividades cantas? ¿Qué canciones te gustan? ¿Qué cuento, anécdota o historia nos puedes relatar? ¿Cuándo cuentas historias?

Algunas de las personas, lugares y/o actividades sugeridas para grabar los videos cantando o contando, tomando como ejemplo municipios del departamento del Atlántico son: Amas de casa en sus quehaceres diarios o amamantando o arrullando a los niños, vendedoras de bollo, alimentos o productos artesanales, pescadores, cultivadores, en la escuela, grupos de jóvenes, en la iglesia, en un velorio o rito fúnebre como misa de los ocho días.

\section{Al ritmo de la mirada}

Observen los videos en clase y vuelvan a responder a partir de ellos la pregunta inicial 
Entre ustedes hagan videos contando o cantando, también podrían grabar el relato de algunas experiencias vividas mientras realizaban la actividad.

\section{Al ritmo del corazón}

Piensa en algo que consideres que cuando te lo dijeron o contaron ha marcado tu vida y permanecerá en tu memoria

\section{Al ritmo del talón}

¿Qué podemos hacer para conservar y fortalecer las manifestaciones orales de nuestra comunidad?

\section{Guías de lectura: Amantina Valoyes}

Amantina sólo tenía una tambora vieja para marcar el ritmo. Se paraba frente a todos y con la coquetería de su raza empezaba la clase con un "punta - talón, punta - talón - punta", meneando graciosamente la cabeza de un lado a otro. Tarareaba el Danubio azul y cerraba los ojos para soñar que daba vueltas y vueltas en los brazos de un apuesto príncipe [...]

Nicasia Mena, una negra grande y gorda muy amiga de Amantina, vino desde Tadó a bailá vars y a traerle un abanico que su abuela guardaba como un tesoro, pero que había accedido a prestarle a La Acaremia para poder ensayar los pasos en que punta - talón, punta - talón - punta van rapidísimo y se abre y se cierra el abanico en la misma dirección que va marcando la cabeza.

El entusiasmo con la llegada del abanico fue general. Uno por uno atravesaron el galpón valseando con el abanico, soñando con el abanico, abanicándose con el abanico. Y el abanico aprendió a soplar, a bailar, a valsear con el dom - dom de la tambora y el viento húmedo del río. (Posso, 2011, p. 73).

\section{Al ritmo del pensar}

Describe y comenta lo que ocurre alrededor de la tambora y el abanico, ¿qué representa cada uno?

Haz una lista de los ritmos musicales favoritos para escuchar y bailar, ¿cuáles de ellos consideras locales?, ¿cuáles extranjeros?

\section{Al ritmo de la lengua}

Trae un objeto que tenga algunas de las siguientes características: represente para ti un valor emocional o afectivo, que sea antiguo, o haya sido guardado por algunos años y represente algún recuerdo o hecho del pasado; esté relacionado con una anécdota o historia personal, familiar.

Los objetos cuentan historias. Explica al grupo: ¿por qué lo escogiste?, ¿cuál es la historia detrás de él?, ¿qué representa para ti? Pero contándolo en primera persona, personificando el objeto, de manera que parezca que ese objeto eres tú.

\section{Al ritmo de la mirada}

Escoge uno o varios objetos que te hayan llamado la atención y haz una recreación artística de ellos y de lo expuesto por tus compañeros. Algunas ideas:

Escribe una historia, poesía o canción. Haz un video, exposición fotográfica o stop motion (animación en volumen o animación fotograma). Realiza un dibujo o modelado en plastilina o arcilla.

\section{Al ritmo del corazón}

Prepara en grupo una coreografía usando los objetos y expresando las emociones que generan.

\section{Al ritmo del talón}

¿De qué manera este tipo de lecturas y actividades podrían aportar al crecimiento sociocultural de tu comunidad? 


\section{Referencias}

Krakusin, M. (2007). Cuerpo y texto: el espacio femenino en la cultura afrocolombiana en María Teresa Ramírez, Mary Grueso Romero, Edelma Zapata Pérez y Amalia Lú Posso Figueroa. En Ortíz, L. (ed.), Chambacú, la historia la escribes tú: ensayos sobre cultura afrocolombiana. Madrid: Iberoamericana.

Motta, N. (1997). Hablas de selva y agua. La oralidad afropaćfica desde una perspectiva de género. Bogotá: Universidad del Valle.

Panza, S. (2018). Resignificación de cuerpo y espacio en Vean vé mis nanas negras de Amalia Lú Posso Figueroa (tesis de maestría). Universidad del Atlántico, Barranquilla, Colombia.

Patiño, A. (2005, 11 de mayo). El regionalismo en Vean vé, mis nanas negras de Amalia Lú Posso Figueroa. Estudios de Literatura Colombiana. Recuperado de https://aprendeenlinea.udea.edu.co/revistas/index.php/ elc/article/view/17353

Posso Figueroa, A. (2011) Vean Vé mis nanas negras. Bogotá, Colombia: Brevedad.

Vejarano, S. (2012). Cuerpos en la literatura: una delgada linea entre la historia y la ficción: breve selección de obras colombianas y latinoamericanas, sus personajes, sus escritores, sus historias y sus cuerpos. Cali, Colombia: Editorial Bonaventuriana. 